1 Universidade Federal do Recôncavo da Bahia (UFRB) - Cruz das Almas (BA), Brasil.

camila.goes@ufrb.edu.br

2 Universidade Estadual de

Feira de Santana (UEFS)

- Feira de Santana (BA),

Brasil.

\section{Saúde no campo: caminhos percorridos pelo Movimento dos Trabalhadores Rurais Sem Terra (MST)}

\author{
Health in the countryside: paths taken by the Landless Rural Workers \\ Movement (MST)
}

Camila Goes da Silva ${ }^{\mathbf{1}}$, Clara Aleida Prada ${ }^{\mathbf{2}}$

DOI: 10.1590/0103-11042019S804

RESUMO A saúde tem múltiplos fatores determinantes, entre eles, a posse da terra e a posição de classe de um grupo populacional. Este artigo teve como objetivo debater o conceito saúde do campo a partir da construção do conceito ‘do campo' no caminho percorrido pela educação e pela saúde dentro do Movimento dos Trabalhadores Rurais Sem Terra (MST). Foi realizada a análise documental de textos desenvolvidos pelo próprio MST e de pesquisas sobre o movimento, assim como entrevistas já publicadas a lideranças. O conceito ‘do campo' tem sido amplamente debatido pelo Setor da Educação e Saúde no MST ressaltando seu significado como lugar de vida, e não somente de produção, que não deve ser definido só a partir do antagonismo da cidade. A educação do campo é pensada pelos próprios camponeses favorecendo sua identidade, costumes e cultura. A saúde é preocupação do MST desde 1980 quando foram criadas as equipes de saúde nas primeiras ocupações de terras. O MST tem desenvolvido encontros e documentos de discussão sobre o tema, refletindo sobre a saúde e reivindicando, além da atenção médica com prioridade à promoção e prevenção, o respeito às diferenças culturais e o fortalecimento das práticas não convencionais em saúde.

PALAVRAS-CHAVE Saúde. Classe social. Educação. População rural.

\begin{abstract}
Health has multiple determinants, including land tenure and the class position of a population group. This article aimed to discuss the concept of health in the countryside, based on the construction of the concept of 'the countryside' on the path of education and health within the Landless Rural Workers Movement (MST). Documentary analysis of texts developed by the MST itself and research on the movement was carried out, as well as interviews already published to leaders. The concept of 'the countryside' has been widely debated by the Education and Health Sector in the MST, emphasizing its meaning as a place of life, and not only of production, which should not be defined only from the antagonism of the city. Rural education is thought by the peasants themselves, favoring their identity, customs and culture. Health has been a concern of the MST since 1980 when health teams were created in the earliest land occupations. The MST has developed meetings and discussion papers on the subject, reflecting on health and claiming, in addition to medical care with priority to promotion and prevention, respect for cultural differences and strengthening of unconventional practices in health.
\end{abstract}

KEYWORDS Health. Social class. Education. Rural population. 


\section{Introdução}

No Brasil, o principal processo de luta pela democratização da saúde foi liderado pelo Movimento da Reforma Sanitária (MRS), iniciado na década de 1970. As concepções de saúde, elaboradas por esse movimento, estavam pautadas na determinação social e histórica, além de associar os aspectos culturais, psicológicos e subjetivos ${ }^{1}$.

Nesse sentido, no relatório final da VIII Conferência Nacional de Saúde (CNS), realizada em 1986, em um contexto de intensa luta pela redemocratização do Brasil e um marco na construção do Sistema Único de Saúde (SUS), diz-se que:

[...] a saúde é a resultante das condições de alimentação, habitação, educação, renda, meio ambiente, transporte, emprego, lazer, liberdade, 'acesso e posse de terra' e acesso a serviços de saúde. É assim, antes de tudo, o resultado das formas de organização social da produção, as quais podem gerar grandes desigualdades nos níveis de vida. A saúde não é um conceito abstrato. Define-se no contexto histórico de determinada sociedade e num dado momento do seu desenvolvimento, devendo ser conquistada pela população em suas lutas cotidianas ${ }^{2(4)}$.

O conceito de saúde expresso na Constituição Federal de 1988 apresenta uma forte influência dessa elaboração da VIII CNS e do MRS. A Lei $n^{\circ} 8.080$ estabelece que

a saúde tem como fatores determinantes e condicionantes, entre outros, a alimentação, a moradia, o saneamento básico, o meio ambiente, o trabalho, a renda, a educação, o transporte, o lazer, o acesso aos bens e servicos essenciais ${ }^{3(1)}$.

$\mathrm{O}$ acesso e a posse da terra foram excluídos dos determinantes sociais no texto constitucional, validando a força da burguesia agrária na composição do Estado brasileiro.
Os determinantes sociais são a manifestação da posição de classe de um grupo populacional que condiciona seu estado de saúde, em muitas situações, mais do que as condições biológicas ou o estilo de vida. As iniquidades podem ser amenizadas, mas jamais anuladas, por sistemas de saúde públicos e serviços de assistência social. Barradas ${ }^{4(19)}$ afirma que

consideramos os padrões de saúde e doença como as consequências biológicas dos modos de vida e trabalho próprios de cada grupo social, determinados pela organização econômica e pelas prioridades políticas da sociedade.

Em 2005, foi criada a Comissão de Determinantes Sociais de Saúde (CDSS) dentro da Organização Mundial da Saúde (OMS). Essa comissão propôs dois tipos de determinantes sociais para a saúde: os estruturais e os intermediários 5 . Os determinantes estruturais são compostos pelas relações de gênero e de etnia, pela organização social e classe social e pelo contexto sociopolítico e econômico. Esses fatores determinam o nível de escolaridade, emprego e renda dos indivíduos. São considerados determinantes estruturais, pois agem e condicionam os determinantes intermediários, impactando na equidade em saúde da sociedade.

Os determinantes intermediários são os fatores relacionados com o estilo de vida e de comportamento, os fatores biológicos e psicossociais, assim como as circunstâncias materiais, como: trabalho, alimento e moradia. O sistema de saúde também faz parte dos determinantes intermediários. Tais fatores atuam de forma diferenciada no estado de saúde, de acordo com a posição socioeconômica dos indivíduos ou das classes ${ }^{6}$.

O paradigma moderno compreende dois mundos opostos: a cidade, cosmopolita, avançada e pujante; e o campo, atrasado, local e simples. Dessa forma, é mantida a tendência na política e na gestão de entender o desenvolvimento como o passo do atraso ao moderno, do rural ao urbano, do agrícola ao industrial. 
Nessa lógica, os governos da América Latina reafirmaram o modelo civilizatório imperante, sua lógica produtivista, seu modelo energético não sustentável e colocaram a produção petrolífera, agroindustrial e da mineração como a única via para combater a crise e enfrentar as imperiosas necessidades do desenvolvimento ${ }^{5}$.

No Brasil, a posse da terra tem sido objeto de reinvindicações dos movimentos populares que têm, por objetivo, a Reforma Agrária. Essa luta enfrenta os latifundiários contra os trabalhadores sem terra em um antagonismo entre classes sociais com objetivos distintos, produção capitalista do agronegócio baseado no monocultivo e voltado para a exportação contra a luta pelo direito de ter um pedaço de chão para a produção de alimentos, para o consumo interno. Nesse âmbito, a correlação de forças que tem prevalecido desde a formulação da Constituição Federal de 1988, assim como na legislação posterior, não levou a uma reforma agrária estrutural, "permitindo, no máximo, políticas de assentamos sujeitas a vicissitudes de ordem política, orçamentária e operacional"7(400).

Dessa forma, o objetivo deste artigo é debater o conceito 'saúde do campo', a partir do caminho percorrido pelo Setor de Saúde do Movimento dos Trabalhadores Rurais Sem Terra (MST). A pesquisa foi realizada por meio da análise documental e faz parte da dissertação de mestrado intitulada 'Saúde do Campo no assentamento Tiradentes, em Mari, na Paraíba', defendida na Fundação Oswaldo Cruz, Escola Nacional de Saúde Pública Sergio Arouca em 2016. Nessa pesquisa, foram identificados materiais produzidos pelo MST, nos quais existe referência ao tema educação do campo e saúde para construir a narrativa.

\section{Resultados e discussão}

O MST foi fundado em 1984, no Paraná, com os objetivos de lutar pela terra, pela reforma agrária e por mudanças sociais no País. A partir de 1985, as ocupações se multiplicaram pelos estados, e a organização se fortaleceu de forma autônoma a partidos e governos. Parte de suas reivindicações foi contemplada pela Constituição Federal de 1988, a exemplo da definição sobre a função social da propriedade rural, porém, a implementação de medidas neoliberais nos governos posteriores e a consequente repressão limitaram o seu alcance. O MST tem liderado a luta pela Reforma Agrária com ocupações de terra improdutivas e marchas pelo Brasil, defendendo uma sociedade justa, fraterna e igualitária ${ }^{8}$.

\section{A construção do termo 'do campo' pelo MST}

O conceito 'do campo' vem sendo amplamente debatido pelo Setor de Educação do MST, desde o I Encontro Nacional de Educadoras e Educadores da Reforma Agrária (Enera) em 1997. Este evento foi palco de alguns marcos históricos: a primeira Ciranda Infantil Nacional, espaço de educação, lazer e cuidado construído para as crianças durante as ações e atividades do movimento; também se realizou a primeira reunião com as universidades que desencadeou na criação do Programa Nacional de Educação na Reforma Agrária (Pronera) em 1998; por fim, o MST convocou um encontro de educadores de todo o meio rural na Conferência Nacional por uma Educação Básica do Campo em $1998^{9}$.

No processo de construção dessa Conferência, iniciou-se a Articulação Nacional por uma Educação do Campo, na qual se debateu: a importância de reafirmar o campo como lugar de vida, e não só de produção; a necessidade de lutar por políticas públicas para as populações camponesas; assim como construir projetos políticos-pedagógicos vinculados à realidade do campo. As escolas, além de se concentrarem nas sedes dos municípios, possuem um projeto educativo baseado na realidade urbana. Isto é contraditório com a realidade dos educandos de origem camponesa. Defendeu-se que "A maioria das sedes dos pequenos municípios é rural, pois sua população vive direta ou indiretamente da produção do campo"10(11). 
Denunciaram-se os problemas da educação do campo: falta de escola, de infraestrutura, de qualificação docente, de políticas de valorização do magistério e de apoio às inovações. Constatou-se um alto índice de analfabetismo nas áreas. Por fim, observou-se que, nas escolas formais, as crianças e jovens são deseducados a viver no campo, prejudicando sua identidade camponesa. Diz Kolling10(12), "crianças e jovens têm o direito de aprender da sabedoria dos seus antepassados e de produzir novos conhecimentos para permanecer no campo".

A Articulação Nacional por uma Educação do Campo estabeleceu dois objetivos gerais: mobilizar o povo para lutar por políticas públicas que visassem à escolarização dos camponeses e refletir, debater e construir propostas político-pedagógicas de educação do campo. Propôs-se um projeto educativo do campo articulado a um Projeto Nacional de Educação, pautado em uma educação para humanização plena do ser humano.

O direito à educação somente será garantido no espaço público. Nossa luta é no campo das políticas públicas e o Estado precisa ser pressionado para que se torne um espaço público. Os movimentos sociais devem ser guardiões desse direito e o Estado deve ouvir, respeitar e traduzir em políticas públicas as demandas do povo que vive no campo'10(14).

Nos anos seguintes, a luta continuou nos estados, e veio a formulação das Diretrizes Operacionais para Educação Básica nas Escolas do Campo"11. Portanto, a Educação do Campo caracteriza-se por ser, ao mesmo tempo, um fenômeno, um processo e uma modalidade pedagógica construída pelos trabalhadores do campo em luta. Nasceu enquanto reivindicação popular de diversos movimentos de luta pela terra. Atualmente, é também uma política pública, mas continua existindo enquanto experiência fora da estrutura estatal. É uma contraposição de forma e conteúdo à educação rural proposta pelo Estado brasileiro, por isso a negação da palavra rural e a proposição da expressão do campo ${ }^{12}$.
Em 2002, a Articulação Nacional por uma Educação do Campo declarou a necessidade de construção de uma escola que esteja no campo, mas que também seja do campo: uma escola política e pedagogicamente vinculada à história, à cultura, às causas sociais e humanas dos sujeitos do campo e não um mero apêndice da escola pensada na cidade10(13).

Discutiu-se o emprego do termo Educação 'do' ' ‘no' Campo, em contraposição a Educação para o campo, elaborada por agentes externos à realidade camponesa:

No: o povo tem o direito de ser educado no lugar onde vive. Do: o povo tem direito a uma educação pensada desde o seu lugar e com a sua participação, vinculada à sua cultura e às suas necessidades humanas e sociaisio(26).

Essa proposta evidencia que o campo é o lugar de produção e reprodução da vida de milhares de camponeses, como os quilombolas, indígenas, assentados, ribeirinhos, povos de floresta, pequenos agricultores, caboclos, boia-fria, sem-terra, agregados, meeiros, pescadores etc., que resistem à expulsão imposta pelo modelo agrícola dominado pelo agronegócio. Esses povos têm uma raiz cultural própria, um jeito de trabalhar, de ver e viver no mundo que é distinto do meio urbano. Por isso, a Educação do Campo considera que todos devem ter o direito a pensar o mundo, a partir do lugar onde vive, isto é, de sua própria realidade.

O povo que vive no campo tem que ser o sujeito de sua própria formação. Não se trata, pois, de uma educação ou uma luta para os, mas sim dos trabalhadores do campo e é assim que ela deve ser assumida por todos ${ }^{10(20)}$.

\section{A saúde no MST}

Da mesma forma como a educação não está pensada para a permanência do camponês 
no seu território, a resposta às necessidades de saúde dessas populações do campo também se caracteriza pelo abandono do Estado. No Brasil, ainda são observadas altas prevalências de doenças infecciosas, como dengue, tuberculose, leishmaniose e leptospirose etc., que refletem precárias condições de vida e limitações no acesso aos serviços de saúde. Além disso, observa-se um aumento significativo do sobrepeso e da obesidade, assim como das doenças crônicas não transmissíveis. Nesse sentido, o conceito de Determinantes Sociais da Saúde define que as condições sociais nas quais os indivíduos nascem, crescem, vivem, trabalham e envelhecem são responsáveis pelas enormes diferenças na situação de saúde entre países e entre os grupos populacionais do interior deles ${ }^{13}$.

O Movimento pela Reforma Sanitária Brasileira conformado por pesquisadores, movimento estudantil, movimento de profissionais da saúde e sindicatos foi uma reforma social geral com o objetivo da mudança no estilo de vida. Seus aspectos centrais são a democratização da saúde, do Estado e da sociedade alinhada a outras mobilizações sociais e políticas rumo à construção de políticas públicas universalistas e igualitárias, entre elas, o movimento pela Reforma Agrária.

A saúde figura entre as preocupações dos Sem Terra desde o início da organização, com a conformação das equipes de saúde com função assistencial e de cuidado em saúde. O processo de autofazer-se do ser social Sem Terra se inicia quando os indivíduos se rebelam contra a sua condição de não possuir uma terra e ocupam coletivamente um latifúndio. Por meio dessa ação, o sem-terra rompe com a lei sagrada da propriedade privada em detrimento da vida e do trabalho; toma para si a tarefa de alterar a realidade e, em consequência, seu destino; e aprende que a ação coletiva tem mais condições de acumular força política e legitimidade diante da sociedade do que a ação individual.

A ocupação da fazenda Annoni, no Rio Grande do Sul, em 1980, compôs uma série de lutas e ocupações de terra que constituem as origens do $\mathrm{MST}^{\mathbf{1 4}}$. Já naquela ocupação, equipes de trabalho foram montadas, entre elas, a Equipe de Saúde, responsável por cuidar dos doentes, organizar a ficha para atendimento pelo posto de saúde e produzir remédios caseiros. Havia também uma equipe de higiene, responsável pela construção de fossas e pela limpeza do acampamento ${ }^{\mathbf{1 4}}$.

Segundo Rosângela Santos, militante do MST desde 1986, integrante do Coletivo Nacional de Saúde e assentada no Espírito Santo:

O trabalho com a saúde no MST começou ainda com as primeiras ocupações de terra. Quando eram formadas as equipes internas do acampamento, já se incluía a da saúde, que normalmente tinha a função de cuidar das pessoas com algum problema de saúde. Foi assim que em vários estados o MST começou a desenvolver práticas em saúde. Começou a produzir remédios caseiros, homeopáticos, desenvolver técnicas de massagem e realizar cursos de primeiros socorros. Cada estado tinha o seu jeito de organizar. Até então não havia Setor de Saúde, apenas equipe ${ }^{15(2)}$.

As ações de saúde nasceram no MST focadas nas doenças e nas atividades de cura, em resposta aos problemas de saúde imediatos que se apresentavam nos acampamentos e assentamentos. Apesar de, no dia a dia dos Sem Terra, a saúde se impor como necessidade primordial, foi somente em 1995 que a relação entre condições de vida no campo e a saúde começou a aparecer nos documentos do MST:

Houve melhoria nas condições de vida da população do meio rural em algumas regiões, especialmente no Sul e Sudeste. Mas a imensa maioria da população rural continua à margem dos benefícios do progresso econômico e do avanço das forças produtivas. Os indicadores sociais das regiões rurais sobre o consumo de luz elétrica, utilização de eletrodomésticos, níveis de alfabetização, mortalidade infantil, nível de escolaridade, número de médicos, nível de renda per capita são alarmantes e se equiparam às regiões mais pobres do mundo. 
Revelam o grau de discriminação social, econômica e política a que foram submetidas pelas oligarquias e elites rurais. Existe fome no meio rural. Dos 32 milhões de brasileiros que passam fome diariamente e são considerados indigentes, mais de metade vive no meio rural. Há um aumento da miséria no meio rura|16(15).

O texto segue ressaltando que as mulheres do campo são as que mais sofrem com a péssima situação de vida do campesinato, pois se soma à opressão de gênero pautada no machismo. As mulheres camponesas trabalham mais do que os homens, visto que, além das atividades da produção, são responsáveis pelos afazeres domésticos. Apesar disso, são impedidas de participar da economia doméstica.

As formulações e práticas do MST avançaram inicialmente em relação à luta pela terra, à formação, à produção e à educação. No III Congresso Nacional do MST, em 1995, foi colocada a necessidade da saúde prosseguir no movimento para além das demandas imediatas ${ }^{\mathbf{1 7}}$. No programa de Reforma Agrária divulgado nesse período, havia uma reivindicação que fazia referência à saúde: "Atendimento médico-hospitalar e programas de saúde preventiva e medicina alternativa gratuitos"16(25). A saúde passava a constar no programa de Reforma Agrária, mas ainda sob uma influência predominante do paradigma biomédico, em consonância com a ideologia predominante da sociedade. Reafirmando a crença que quanto mais acesso a serviços de saúde, isto é, consultas com profissionais (de preferência, o médico especialista), exames complementares e possibilidades terapêuticas, mais estará cuidando da sua saúde ${ }^{\mathbf{1 8}}$.

Somente em 1998 a saúde se estruturou na organicidade do MST, após uma oficina nacional para socialização de experiências, em Brasília, que contou com a representação de 23 estados e discutiu os princípios da saúde do movimento:
Luta pela valorização da vida; Acesso ao conhecimento e à informação; Saúde como dever do Estado; Atenção integral à saúde; Prioridade à promoção e à prevenção; Respeito às diferenças culturais; Fortalecimento das práticas não convencionais em saúde; Saúde como uma conquista de luta popular19(12-13).

Como resultado, foi criado o Coletivo Nacional de Saúde que elaborou o 'Caderno de Saúde no 1' (Lutar por Saúde é Lutar pela Vida), em abril de 1999 (figura 1). O caderno inicia dizendo:

Sabemos que para garantir a nossa saúde é preciso muito mais que assistência médica e hospitalar. É preciso garantir condições para que a gente não fique doente, pois só temos saúde quando temos uma vida digna. É possível ter saúde quando não temos terra para plantar? Quando nossos filhos não estão na escola? Quando não há estradas decentes, não tem luz, água potável, comida? [...] Por isso, precisamos de muita organização para lutar contra este sistema neoliberal que gera doença e morte. [...] Entendemos que para ter saúde é preciso que as condições de vida sejam garantidas: terra e trabalho; condições de moradia; educação de qualidade; alimentação saudável, sem venenos e conservantes; meio ambiente limpo e conservado; lazer e bem-estar, etc. Assim lutar pela saúde é resgatar os valores de solidariedade, da justiça, onde as pessoas sintam prazer pelo que fazem, pelo que são e não pelo que tem, e garantir uma vida saudável onde seja respeitado o direito de todos ${ }^{19(5)}$.

O documento segue com informações referentes ao SUS, princípios e formas de participação social. Em um primeiro momento, o Setor de Saúde manteve suas ações centradas na assistência, mediante o uso das plantas medicinais e da atuação em situações de adoecimento, nas comunidades e nas ações do movimento ${ }^{20}$. 
Figura 1. Capa do 'Caderno de Saúde no 1'

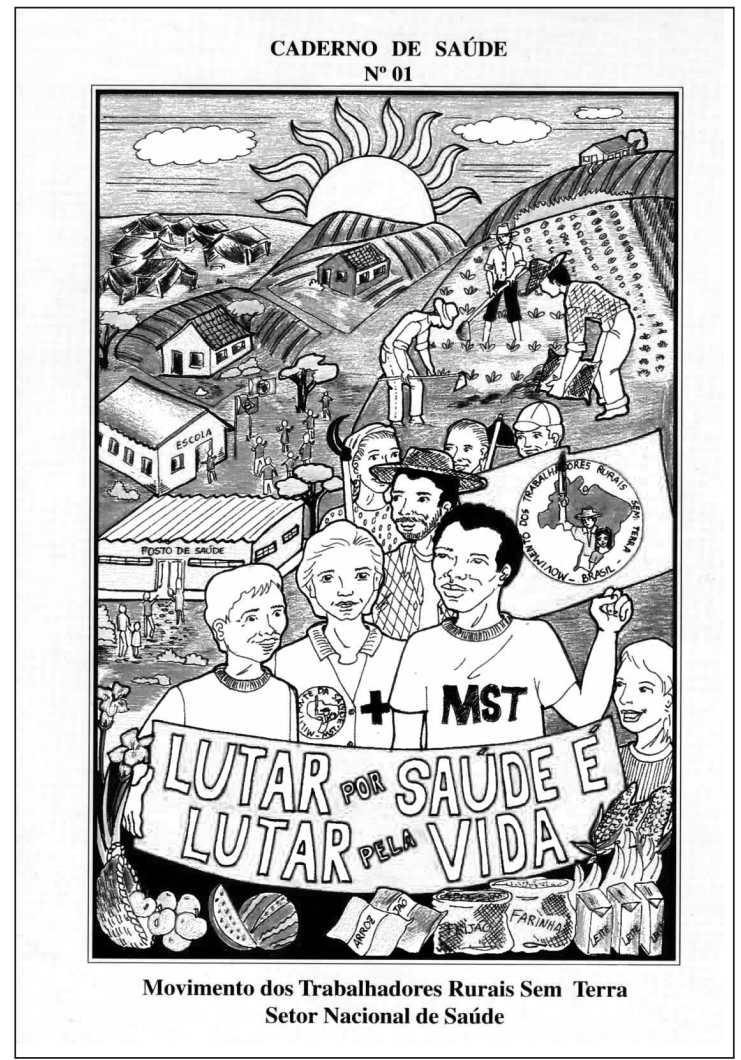

Fonte: Caderno de Saúde ${ }^{19}$

O Setor de Saúde do MST e a Fundação Oswaldo Cruz - Fiocruz (representada pela Unidade Farmanguinhos) iniciaram uma parceria para desenvolvimento de um complexo agrofarmacêutico em áreas de reforma agrária. O projeto intitulado 'Programa Terra e Saúde' previa desde o cultivo de plantas medicinais, em hortas comunitários, até o seu beneficiamento em laboratórios equipados para a produção de fitoterápicos que pudessem ser vendidos para o SUS. Desse projeto, foram elaboradas duas cartilhas pelo Coletivo Nacional de Saúde: o 'Caderno de Saúde no 2', em 1999, 'Programa Terra e Saúde: das plantas construindo uma nova saúde'; e o 'Caderno no 4 ', em 2000 , 'Cultivo de plantas medicinais' (figura 2). 
Figura 2. Capa do 'Caderno de Saúde no 4 '

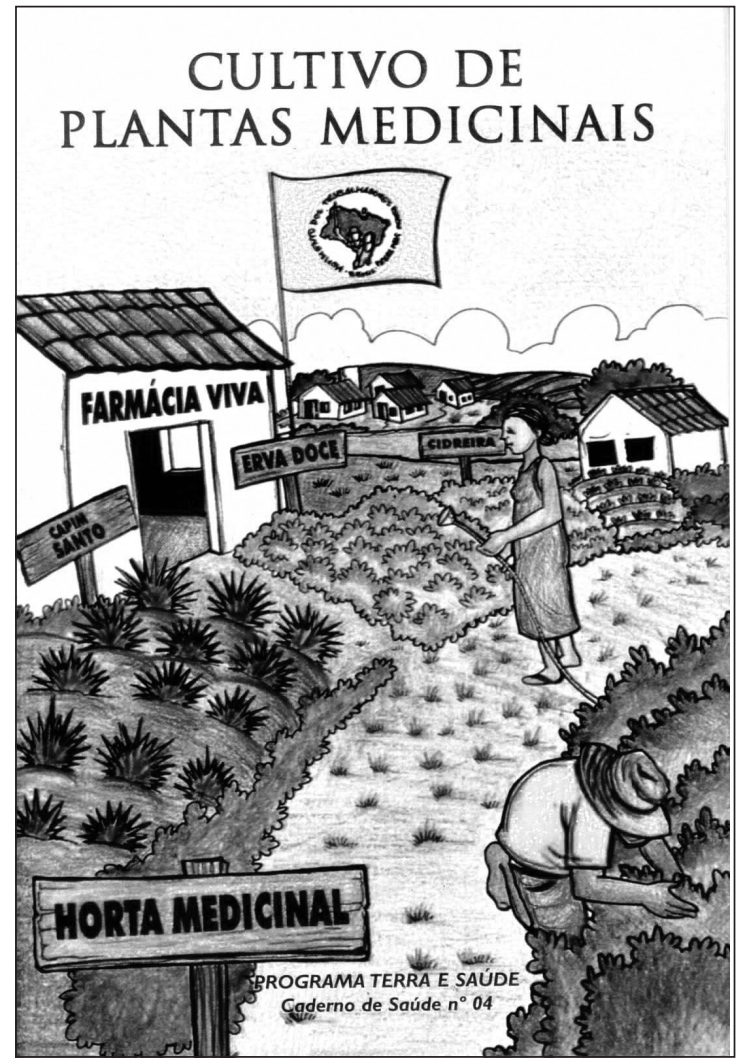

$\mathrm{O}$ 'Caderno $\mathrm{n}^{\mathrm{o}}$ 2' reforçou a visão ampliada de saúde, teceu críticas às políticas neoliberais do governo do então presidente Fernando Henrique Cardoso, que priorizava os interesses do capital em detrimento dos direitos sociais, como a saúde. Apresentou o projeto Programa Terra e Saúde como uma possibilidade de solução de problemas básicos de saúde, por meio do uso de plantas medicinais, dentro e fora dos assentamentos e acampamentos. Reforçou também a necessidade de usar o projeto como fator mobilizador da comunidade e de fortalecimento de práticas populares de cuidado ${ }^{\mathbf{2 1}}$.

Desenvolver através de um programa de saúde popular, a assistência social para a população. $\mathrm{O}$ acesso à saúde é uma das áreas mais sensíveis do nosso povo, mas este trabalho assistencial não poderá de maneira alguma se transformar em paternalismo e alienação e sim em um espaço para reduzir os problemas e mobilizar o povo para a luta21(12).

Havia uma idealização de que as práticas populares de cuidado fossem capazes de responder às demandas da saúde, não só das áreas de reforma agrária como de toda a sociedade. Esse projeto não conseguiu alcançar os seus objetivos. No entanto, as plantas medicinais continuaram protagonizando as atuações do Setor de Saúde.

O processo de especialização na saúde e a transformação da saúde em mercadoria, na sociedade capitalista, restringiram os 
profissionais de saúde à cura de doenças, gerando uma medicalização da vida, uma alienação da população em relação ao seu corpo e uma consequente mercantilização dos cuidados em saúde. As práticas populares de cuidado, baseadas no conhecimento empírico construído e repassado ao longo das gerações, estão sendo abandonadas, particularmente nas populações urbanas.

A íntima relação com a natureza e a dificuldade de acesso aos serviços oficiais de saúde têm contribuído para que os camponeses se mantenham como guardiões do conhecimento acerca do cultivo e uso de plantas medicinais ${ }^{22}$. Nesse sentido, o MST atua para potencializar a socialização desse conhecimento dentro e fora das comunidades, assim como na luta por políticas públicas.

No desenrolar desse caminhar, outras frentes de atuação foram sendo construídas pelo Setor de Saúde. Em 1999, em uma parceria com a Universidade de Brasília (UnB) e com a Coordenação Nacional de DST/Aids do Ministério da Saúde, o Setor de Saúde realizou uma pesquisa nacional, quantitativa, de investigação das condições de saúde dos trabalhadores rurais de assentamentos e acampamentos de Reforma Agrária. Em especial, a partir desse trabalho, o tema da saúde ambiental foi incorporado à pauta da saúde do MST ${ }^{17}$.

Em 2000, o Coletivo Nacional de Saúde realizou a I Oficina de Produção de Materiais Educativos do Setor de Saúde, quando se propôs a apropriação dos referenciais do MRS brasileira, "passando a incorporar elementos como direito à saúde, educação em saúde, vida saudável e sua relação com a transformação social”17(42). Esse encontro resultou na elaboração do 'Caderno de Saúde no 5' (Construindo o Conceito de Saúde do MST), na forma de cartilha ilustrada e álbum seriado (figura 3). Esse material tornou-se referência para problematização do conceito de saúde no movimento. A definição de saúde do MST expresso nesse caderno é bastante semelhante ao que foi concebido na VIII CNS, inclusive destacando a importância do acesso à terra para garantia de saúde às populações do campo.

\footnotetext{
Uma sociedade com saúde é onde os homens e mulheres vivem com liberdade para participar e ter seus direitos respeitados. Onde a renda e a riqueza sejam distribuídas com igualdade. Com terra, trabalho, moradia, alimentação, educação, lazer, saneamento básico, transporte, saúde pública, cultura, meios de comunicação, energia elétrica - onde haja justiça, igualdade, participação e organização! Mas para que isso se torne realidade, é necessária a organização de todos os trabalhadores e trabalhadoras para lutar por uma sociedade justa e saudáve|23(12).
}

Os desafios apontaram para a necessidade de um projeto de formação e educação em saúde dos integrantes do setor saúde do movimento. Em 2000, houve a primeira turma do Curso Técnico em Saúde Comunitária pelo Instituto Técnico de Capacitação e Pesquisa da Reforma Agrária (Iterra), em Veranópolis (RS), com educandos de todo o Brasil12. Nos anos seguintes, outras turmas desse curso aconteceram no Iterra e em outros estados, assim como Curso Técnico de Enfermagem e de Saúde e Ambiente ${ }^{15(2)}$. 
Figura 3. Capa do 'Caderno de Saúde no 5'

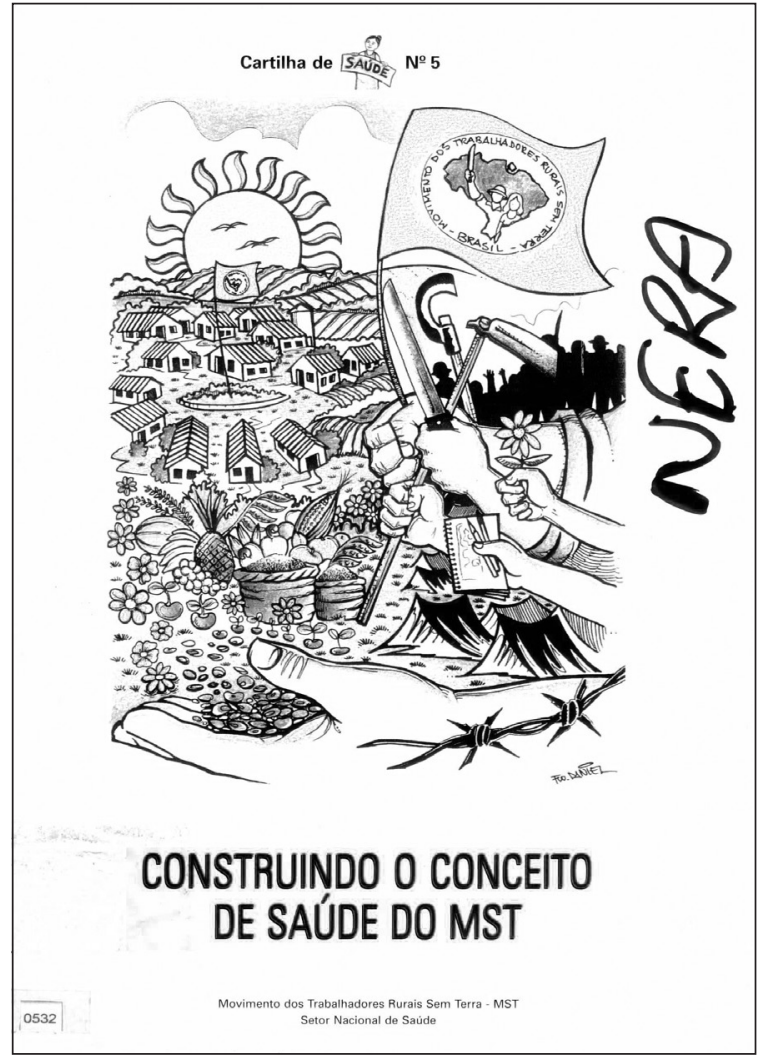

Fonte: Caderno de Saúde $\mathbf{2 3}^{\mathbf{3}}$

Em 2003, o MST lançou a cartilha 'A Reforma Agrária que precisamos’ para ser debatida nos núcleos de base dos assentamentos e acampamentos, tendo por referência as discussões já iniciadas nas instâncias estaduais e nacionais do movimento. No capítulo sobre a organização do assentamento, há um ponto destinado à saúde. No entanto, a visão da saúde permanece restrita à produção de medicamentos naturais e à prevenção de doenças sexualmente transmissíveis e à dependência química. O documento finaliza

Nossa preocupação é que se tenham programas de orientação das famílias para evitar que fiquem doentes, melhorando sua alimentação, seus cuidados com a saúde, com a higiene, tendo orientação médica e preventiva e de qualidade $\mathbf{2 4 ( 3 0 )}$.

Nesse documento, o conceito de saúde está influenciado pelo paradigma biomédico, de patogenia e profilaxia e reivindica a importância do acesso a serviços de promoção e prevenção, sendo, porém, uma visão restrita de saúde.

De forma contraditória, os integrantes do Coletivo de Saúde na oficina sobre o processo saúde-doença, em 2004, concluíram que:

O conceito de saúde envolve a 'capacidade de reagir' frente à opressão e a tudo que fere sua autonomia como ser humano, pois a busca pela saúde está refletida no fim do latifúndio, do capitalismo, da violência, de forma a 
se libertar do sistema atual. Consideram que a maneira de reagir é determinada pelo meio em que vivem. Avaliam, portanto, que não basta ter a terra, mas deve ser forjado novo jeito de viver, com agricultura que não utilize venenos para produzir alimentos, visando uma produção saudável25(45).

Ainda nessa oficina, os integrantes do Coletivo de Saúde disseram que, apesar dos avanços no debate dentro do setor, ainda era comum a visão no movimento e na base de que sua função se limitava a cuidar dos doentes ${ }^{25}$. Nesse momento, o Setor de Saúde já tinha um vasto leque de atuação.

Em 2005, o Coletivo Nacional de Saúde realizou encontros para sistematização de atividades de educação em saúde realizadas pelos estados, resultando no caderno 'Relato de experiências em saúde do Movimento Sem Terra'. Este contém as experiências de educação em saúde, realizadas por 13 estados, cujos temas principais foram DST/Aids, sexualidade e afetividade, plantas medicinais, saúde da criança e desnutrição, organicidade do setor, questão de gênero, juventude, hábitos de higiene, saneamento, dependência química e direito à saúde ${ }^{26}$.

A luta pelo direito à saúde incorporou-se às ações do MST; e, em alguns estados e municípios, os integrantes do setor de saúde passaram a compor o controle social do SUS. Além disso, em 2005, o MST passou a integrar o Grupo da Terra para discutir políticas públicas para a saúde das populações do campo, das florestas e das águas no SUS. Esse grupo instituído pelo Ministério da Saúde por meio da Portaria no 2.460/2005 e atualizado pela Portaria n ${ }^{\circ} 3.257 / 2009$ era composto por representantes de órgãos e entidades públicas e da sociedade civil organizada.

No Caderno do Setor de Formação 'O funcionamento das Brigadas do MST', de 2005, as tarefas do Setor de Saúde começam a ser mais bem destrinchadas:

Construir uma cultura de cuidado com a saúde convivendo e cooperando em nossas áreas de assentamentos; Cultivar novos hábitos de saúde comunitária, combatendo os vícios como o alcoolismo e todos os tipos de drogas; Desenvolver hábitos de cuidados com a saúde, seja através de prática de esportes, na participação em grupos de teatro, pintura, como fazer uso da música, poesia e organizar festas; Organizar o cultivo de hortas medicinais na comunidade e ter em casa o básico de ervas medicinais; Cuidar da casa para que o ambiente de moradia seja agradável. A cozinha, os quartos e todas as dependências da casa devem ser um ambiente saudável; Construir banheiros e sanitários em cada casa e manter os esgotos sob controle; Cuidar e preservar a água para que seja limpa e não corra risco de contaminação com esgotos e agrotóxicos; Plantar árvores frutíferas organizando belos pomares em todas as residências e áreas comunitárias; Cuidar da alimentação, tendo o cuidado de cultivar hortaliças para o consumo diário; Recolher e enterrar o lixo em lugares onde não afeta o meio ambiente; Cuidar do corpo. Cuidar da higiene tomando banho diariamente, trocar a roupa e escovar os dentes, consultar um dentista pelo menos uma vez por ano; Cuidar dos animais domésticos. Vacinar os cães e gatos e desverminá-los periodicamente; Cuidar da amizade, alegria e da solidariedade. A felicidade é a principal fonte de saúde ${ }^{27(2223)}$.

Em 2007, uma nova pesquisa sobre as condições de vida e saúde das populações de assentamentos de reforma agrária foi realizada em cinco estados, em uma parceria com a UnB ${ }^{28}$. Em dezembro desse mesmo ano, o Coletivo Nacional de Saúde lançou um Boletim Informativo atualizando os principais objetivos do setor:

Lutar contra o modelo de saúde capitalista expresso no complexo médico industrial-farmacêutico e no agronegócio, e re-significar a saúde na perspectiva da classe trabalhadora, garantindo a saúde como dever do Estado; incorporar a ética de cuidado como estratégia de promoção, prevenção e atenção à saúde, fortalecer as práticas populares, afirmando a 
cultura e saberes do povo; garantir a participação orgânica e política dos/as militantes em todos os espaços coletivos, baseado nos princípios do MST29(2).

Também redefiniu seus princípios:

Luta pela valorização da vida; Saúde como uma conquista de luta popular; Saúde como direito; Lutar pela consolidação de Políticas Públicas de Saúde; Respeito às diferenças; Fortalecimento das práticas e saberes populares em saúde; Educação permanente em saúde; Socializar os conhecimentos e as informações 29(4).

Não identificamos números do caderno de Saúde publicados no período de 2007 a 2015, mas, em 2010, o 'Caderno n’ 2' da coleção 'Sempre é tempo de aprender' 'Agroecologia, Soberania Alimentar e Cooperação’ apresenta os riscos para a saúde dos agrotóxicos ${ }^{30}$.

Em 2015, realizou-se o encontro do setor nacional de saúde, em Luziânia (GO), sob o lema 'Saúde é a capacidade de lutar contra tudo que nos oprime'. Para a dirigente nacional do setor, Mercedes Zuliani, 'É fundamental construir alianças com outros setores que fazem a luta pela saúde relacionada a um projeto de sociedade' $^{\mathbf{3 1}}$. Nesse encontro, as atividades atuais do setor de saúde foram levantadas, por regiões, destacando-se: cursos formais técnicos e de pós-graduação; fortalecimento da organicidade e da formação de militantes; resgate e potencialização do cultivo e do uso de plantas medicinais e outras práticas populares de cuidado; realização de diagnósticos da situação de saúde das áreas de reforma agrária; luta pelo direito à saúde; discussões de gênero; relação com a agroecologia e produção de alimentos saudáveis, questões sobre saúde e ambiente etc.

Em relação à pós-graduação, uma parceria entre a Escola Nacional de Saúde Pública Sergio Arouca/Fiocruz, a Escola Nacional Florestan Fernandes (ENFF)/MST e o Ministério da Saúde ofereceu o Mestrado Profissional em Trabalho, Saúde, Ambiente e Movimentos
Sociais. Foi uma turma especial que contou com 26 mestrandos de todo o País, de diversos movimentos sociais e trabalhadores do SUS, entre os anos de 2014 e 2016. As dissertações versaram sobre temas como a determinação social da saúde, as políticas públicas de saúde, a saúde do trabalhador, a educação popular em saúde, os conflitos agrários e ambientais, a mulher camponesa, os agrotóxicos, a agroecologia, a organização popular, a educação do campo etc. É notório o destaque dado ao modelo agrícola como determinação do processo saúde-doença, no campo e na cidade.

Em 2015, 17 movimentos sociais realizaram o I Encontro Nacional de Saúde das Populações do Campo, Floresta e Águas, em Brasília, contando com a participação de mais de mil delegados de todo o Brasil, sob o lema 'Cuidar, promover, preservar: Saúde se conquista com luta popular!'. Esse encontro aconteceu paralelamente a XV Conferência Nacional de Saúde para denunciar que os espaços institucionalizados de participação social do SUS não estão sendo capazes de debater as necessidades dessas populações ${ }^{32}$.

O Manifesto elaborado pelas organizações denunciou que o modelo de desenvolvimento imposto pelo capital e gerenciado pelo Estado, representado pelo agro-hidro-mineral negócio é insustentável e causa grandes danos à saúde e ao ambiente. Esse modelo não respeita as formas de produção e reprodução da vida dos sujeitos do campo, floresta e águas. Propõe:

Conceber a saúde como necessidade de organização e mobilização porque sem água potável, sem terra fértil, sem biodiversidade, sem a produção agrícola das/dos sujeitos do campo, floresta e águas, sem o cuidado com a água marinha e os animais, sem formas integrais de cuidado, a saúde não é possível ser conquistada33.

E completa:

[É preciso] dar visibilidade aos nossos territórios e valorizar a preservação de nossas culturas, 
do modo de produção que nos identifica como populações do campo, da floresta e das águas e nossas relações que necessitam do cuidado para com nossa luta que é permanente e de forma coletiva, sempre na expectativa de promover nossos sonhos, cuidar de nossas vidas e preservar nossa memória [...] Enfrentar a medicalização da vida e garantir nossos conhecimentos tradicionais, as ervas, as curas espirituais, os fitoterápicos e outras práticas; Defender a saúde como direito, garantindo que todas as conquistas sejam mantidas bem como é preciso avançar nas transformações econômicas, políticas, sociais do país para que as trabalhadoras e trabalhadores tenham as condições dignas para se conquistar a saúde ${ }^{33(3)}$.

O tema da saúde, portanto, vem ganhando cada vez mais destaque dentro do MST. Também se tornou pauta de outros movimentos de luta pela terra e das comunidades tradicionais (indígenas, quilombolas etc.). A articulação dos movimentos sociais pela saúde do campo, da floresta e das águas, que começou de forma institucional por meio do Grupo da Terra, vem desembocando em novas formas de luta, cujo marco foi I Encontro Nacional de Saúde das Populações do Campo, Floresta e Águas.

\section{Avanços da política de saúde do campo}

A histórica desigualdade no Brasil gerada pela exploração dos recursos naturais mantém a população do campo longe de usufruir condições de vida dignas e do acesso efetivo aos serviços de saúde. Quase três quartos da população do campo (72,2\%) não têm acesso à água potável, explicando que, entre as principais causas de internação nos municípios de pequeno porte com alta proporção de população rural, estão as gastroenterites infecciosas e suas complicações $^{34}$. Essa situação é agravada pela falta de provimento de profissionais nesses municípios, pelas dificuldades geográficas para acesso aos serviços de saúde e pelo incremento da violência nesses territórios.
No período de redemocratização, as desigualdades no campo foram mantidas ao igual que o domínio dos interesses dos latifundiários, assim como também permaneceram as desigualdades em relação à assistência em saúde. O SUS e as diferentes políticas de saúde foram traçadas com enfoque na problemática urbana, sem participação no debate e na formulação das populações do campo.

O Grupo da Terra conformado em 2003, composto por diversas áreas do Ministério da Saúde, outras instâncias de governo e movimentos sociais do campo, elaborou uma proposta de política pública de saúde para a população do campo, que foi aprovada por unanimidade no Conselho Nacional de Saúde em 2008, mas que ficou parada nas instâncias governamentais tripartite até 2011, quando finalmente o Ministério da Saúde publicou a Portaria $n^{0} 2.866$ que instituiu a Política Nacional de Saúde Integral das Populações do Campo e da Floresta ${ }^{35}$.

Ao analisarmos o itinerário até a aprovação dessa política, fica evidente seu caráter de concessão da classe dominante ante a luta de classes que se inseriu dentro da estrutura estatal, a partir da organização e pressão realizada pelos movimentos de luta pela terra e povos tradicionais do campo, da floresta e das águas. Apesar de seu texto ser avançado (ou talvez justamente por isso), essa é uma política que tem enfrentado dificuldades já que não prevê um orçamento específico para sua execução; e apesar da liberação de recurso para sua implantação no ano de 2014, poucos estados e municípios priorizaram a execução dos trâmites burocráticos. Por isso, apesar de passados cerca de oito anos desde sua aprovação, pouco se vê de desdobramento na vida dos assentados e assentadas da reforma agrária.

\section{Considerações finais}

Os resultados do estudo sinalizam a ampla discussão e produção no MST em relação a educação e saúde do campo considerando 
a visão e prioridades do próprio camponês. Nesta reflexão, torna-se cada vez mais evidente as contradições do modelo econômico dominante cujo avanço das forças produtivas servem majoritariamente para a melhoria da produtividade mesmo à custa da saúde dos trabalhadores rurais e da degradação do meio ambiente. Esse modelo traz impactos danosos também para os trabalhadores da cidade, que se alimentam com produtos envenenados com agrotóxicos e que sentem as mazelas das mudanças ambientais.

O MST tem realizado uma ampla discussão sobre as condições de vida e de saúde no campo. Parte dessa contribuição é a própria reflexão sobre o conceito ‘do campo’ ao pensar a educação vinculada à realidade, à história, à cultura e às necessidades dos sujeitos que ali moram. O movimento que luta pela posse da terra reivindica a importância da mudança das condições de vida no campo para a melhoria da qualidade de vida de suas populações. Em um primeiro momento, o interesse no tema da saúde esteve relacionado com a função assistencial da atenção aos problemas de saúde imediatos e produção de remédios caseiros.

\section{Referências}

1. Paim JS. Reforma Sanitária Brasileira - Contribuição para a compreensão e crítica. Salvador: EDUFBA. Rio de Janeiro: Fiocruz; 2013.

2. Anais da $8^{a}$ Conferência Nacional De Saúde; $27-30$ março 1986; Brasília, DF: Centro de Documentação do Ministério da Saúde; 1987.

3. Brasil. Lei no 8.080 de 19 de setembro de 1990. Dispõe
Posteriormente, a reflexão focou nas precárias condições de vida no campo como determinantes dos problemas de saúde por eles sofridos. Cuidado da saúde, prevenção do uso de substâncias psicoativas, atividades de lazer, hortas medicinais, moradia digna, saneamento básico foram relacionados com a promoção da qualidade de vida e de saúde. O MST produz inúmeros cadernos de formação em saúde, promoveu cursos de formação técnica e de pós-graduação em saúde para os assentados em parceria com universidades e com o Ministério da Saúde, participou, com outros movimentos sociais, do Grupo Terra que elaborou a Política Nacional de Saúde Integral das Populações do Campo e da Floresta.

\section{Colaboradores}

Prada CA (0000-0002-4686-2197)* participou da aprovação da versão final do manuscrito. Silva CG (0000-0002-3213-5781)* contribuiu substancialmente para a concepção, o planejamento, a análise e a interpretação dos dados.

\footnotetext{
sobre as condições para a promoção, proteção e recuperação da saúde, a organização e o funcionamento dos serviços correspondentes e dá outras providências [internet]. [acesso em 2016 mar 5]. Disponível em: https://portalarquivos2.saude.gov.br/images/ pdf/2015/setembro/30/Lei-8080.pdf.
}

\footnotetext{
Barradas R. Como e por que as desigualdades sociais fazem mal à saúde. Rio de Janeiro: Fiocruz; 2009.
}

${ }^{*}$ Orcid (Open Researcher and Contributor ID). 
5. Breilh J. Las tres 'S' de la determinación de la vida 10 tesis hacia una visión crítica de la determinación social de la vida y la salud. In: Nogueira RP, organizador. Determinação Social da Saúde e Reforma Sanitária. Rio de Janeiro: Cebes; 2010.

6. Breilh J. Una Perspectiva Emancipadora de la Investigación y Acción, Basada en la Determinación Social de la Salud. In: Taller Latinoamericano de Determinantes Sociales de la Salud, 30 set-02 oct 2008 ; Cidade do México: ALAMES. [acesso em $2016 \mathrm{fev}$ 12]. Disponível em: http://repositorio.uasb.edu.ec/ bitstream/10644/3413/1/Breilh\%2C\%20J-CON-119-Una\%20perspectiva\%20em.pdf.

7. Mendes J. Estado e mercado na reforma agrária brasileira (1988-2002). Estudos Históricos. 2015; 56(28):385-404.

8. Movimento dos Trabalhadores Rurais Sem Terra. Início [internet]. c2014 [acesso em 2019 ago 28]. Disponível em http://www.mst.org.br/nossa-historia/.

9. Boletim da Educação II Encontro Nacional de Educadores e Educadoras da Reforma Agrária - II ENERA. São Paulo: Movimento Dos Trabalhadores Rurais Sem Terra (MST). Setor de Educação; 2014 [acesso em 2020 jan 20]; 2. Disponível em: http://www.reformaagrariaemdados.org.br/sites/default/files/BE\%20 (12).pdf.

10. Kolling EJ, Cerioli PR, Caldart RS, organizadores. Educação do campo: identidade e políticas públicas. Brasília: Articulação Nacional por uma Educação do Campo; 2002.

11. Conselho Nacional de Educação Câmara de Educação Básica. Resolução CNE/CEB 1, de 3 de abril de 2002. Institui Diretrizes Operacionais para a Educação Básica nas Escolas do Campo. [acesso em 2020 jan 20]. Disponível em: http://pronacampo.mec.gov. br/images/pdf/mn_resolucao_\%201_de_3_de_abril_ de_2002.pdf.

12. Caldart R. Educação do Campo. In: Caldart RS, Pereira IB, Alentejano P, et al., organizadores. Dicioná- rio da Educação do Campo. Rio de Janeiro: Expressão Popular; 2012, p. 257-264.

13. Pellegrini A, Buss P, Esperidão M. Promoção da Saúde e seus Fundamentos: Determinantes Sociais da Saúde, Ação Intersetorial e Políticas Públicas Saudáveis. In: Paim J, Almeida-Filho N. Saúde Coletiva, Teoria e Prática. Rio de Janeiro: MedBook; 2014.

14. Morissawa M. A história da luta pela terra e o MST. São Paulo: Expressão Popular; 2001.

15. Coletivo Nacional de Saúde do Movimento dos Trabalhadores Rurais Sem Terra. Entrevista com Rosângela Santos, do Coletivo Nacional de Saúde. Jornal Saúde em Movimento. 2009; 1(1):1-4.

16. Caderno de Formação. São Paulo: Movimento Dos Trabalhadores Rurais Sem Terra (MST). Setor de Formação. Programa de Reforma Agrária. São Paulo; 1995; 23. [acesso em 2020 fev 15]. Disponível em: http://www. reformaagrariaemdados.org.br/sites/default/files/ Caderno\%20de\%20Forma\%C3\%A7\%C3\%A3o\%20 n\%C2\%BA\%2023.pdf.

17. Rückert B. As práticas de saúde no MST do Vale do Rio Doce, MG: Normas e valores na atividade [dissertação]. Belo Horizonte: Faculdade de Educação da Universidade Federal de Minas Gerais; 2012, p. 166.

18. Tesser CD. Medicalização social e atenção à saúde no SUS. São Paulo: Hucitec; 2010.

19. Caderno de Saúde. São Paulo: Movimento dos Trabalhadores Rurais Sem Terra (MST). Coletivo Nacional de Saúde. Lutar por saúde é lutar por vida. 1999; 1 [acesso em 2020 fev 15]. Disponível em: http://www.docvirt.com/docreader.net/DocReader.aspx?bib=BibliotLT\&PagFis $=6421$.

20. Burigo AC. Politecnia e Pedagogia do MST - a construção coletiva de um currículo de Saúde ambiental para a população do campo [dissertação]. Rio de Janeiro: Programa de Pós-graduação de Educação Profissional em Saúde, Fundação Oswaldo Cruz; 2010, p. 157. 
21. Caderno de Saúde. Programa Terra e Saúde: Das plantas construindo uma nova vida. São Paulo. Movimento Dos Trabalhadores Rurais Sem Terra (MST). 1999; 2.

22. Brasil. Ministério da Saúde; Universidade de Brasília; Movimento dos Trabalhadores Rurais Sem Terra. Saúde dos trabalhadores rurais de assentamentos e acampamentos da Reforma Agrária. Brasília, DF; 2001.

23. Caderno de Saúde. São Paulo: Movimento dos Trabalhadores Rurais Sem Terra (MST). Construindo o conceito de saúde do MST. 2000; 5.

24. Movimento Dos Trabalhadores Rurais Sem Terra (MST). A Reforma Agrária que precisamos - Vamos debater nos núcleos de base. São Paulo, Secretaria Nacional, 2003.

25. Carneiro FF. A saúde no campo: das políticas oficiais à experiência do MST e de famílias de "bóias-frias" em Unaí, Minas Gerais, 2005. [tese]. Belo Horizonte: Escola de Veterinária da Universidade Federal de Minas Gerais; 2007.

26. Movimento dos Trabalhadores Rurais Sem Terra. Relato das experiências em saúde do Movimento dos Trabalhadores Rurais Sem Terra (MST). Brasília, DF: MST, 2005.

27. Caderno de formação. O funcionamento das Brigadas São Paulo: Movimento dos Trabalhadores Rurais Sem Terra (MST). 2005

28. Associação Nacional de Cooperação Agrícola; Universidade de Brasília. Pesquisa popular participativa: Condições de vida e saúde populações de assentamentos de reforma agrária. São Paulo: ANCA; 2005.

29. Boletim informativo. Movimento dos Trabalhadores Rurais Sem Terra (MST). 2007; 1.

30. Caderno de educação, Coleção Sempre é tempo de aprender. Caderno n. 2. Agroecologia, Soberania Alimentar e Cooperação. São Paulo: Movimento dos Tra- balhadores Rurais Sem Terra (MST). 2010. [acesso em 2020 fev 15]. Disponível em: http://www.reformaagrariaemdados.org.br/sites/default/files/Caderno\%20EJA\%20-\%20Agroecologia,\%20Soberania\%20 Alimentar\%20e\%20Coopera\%C3\%A7\%C3\%A30\%20-\%20MST,\%202010.pdf.

31. Movimento dos Trabalhadores Rurais Sem Terra. Encontro em Luziânia debate os desafios da saúde do campo [internet]. [acesso em 2015 set 1]. Disponível em: http://www.mst.org.br/2015/06/26/encontro-em-luiziania-debate-os-desafiosda-saude-do-campo.html.

32. Antunes A. Em evento paralelo à $15^{\mathrm{a}} \mathrm{CNS}$, movimentos sociais debatem saúde das populações do campo, floresta e águas [internet]. Rio de Janeiro: Escola Politécnica de Saúde Pública Joaquim Venâncio; 2016. [acesso em 2015 dez 12]. Disponível em: http://www. epsjv.fiocruz.br/index.php?Area=Noticia\&Num=996.

33. Manifesto de Saúde das populações do campo, floresta e águas: Cuidar, promover, preservar: a saúde se conquista com luta popular! $1^{\circ}$ Encontro Nacional de Saúde das Populações do Campo, da Floresta e das Águas; 30 nov a 04 dez 2015 [internet]; Brasília, DF. [acesso em 2015 dez 10]. Disponível em: http://issuu. com/comunicacaompa/docs/manifesto_de_sa_de_ das_popula_e.

34. Matos V, Moura M, Ferreira F. Como garantir o direito à saúde para as populações do campo, da floresta e das águas no Brasil? Saúde debate. 2018; 42(1):302314.

35. Brasil. Ministério da Saúde, Secretaria de Gestão Estratégica e Participativa, Departamento de Apoio à Gestão Participativa. Política Nacional de Saúde Integral das Populações do Campo e da Floresta. Brasília, DF: Ministério da Saúde; 2013.

Recebido em 09/06/2019

Aprovado em 13/09/2019

Conflito de interesses: inexistente

Suporte financeiro: não houve 